\title{
Direkt adeziv restoratif sistemlerle polidiastema tedavisi: İki olgu sunumu
}

\author{
Tuğba Toz Akalın ${ }^{1}$
}

Selcuk Dent J, 2016; 3: 145-150

Basvuru Tarihi: 01 Mart 2016 Yayına Kabul Tarihi: 29 Haziran 2016

\author{
ÖZ \\ Direkt adeziv restoratif sistemlerle polidiastema tedavisi: \\ İki olgu sunumu
}

Diastemaların direkt adeziv restorasyonlarla kapatılması oldukça pratik ve konservatif bir yöntem olarak kabul edilmiştir. Adeziv rezin kompozit teknolojisi, diş hekimlerine herhangi bir madde kaybına neden olmadan dişler arasındaki boşlukları kapatabilme ve dişleri şekillendirebilme olanağ sunmuştur. Bu olgu sunumu polidiastema ve lateral eksikliğine sahip iki bireyin tedavisini içermektedir. Bu olgu sunumlarında diastemalar, herhangi bir preparasyon gerektirmeksizin tek seansta direkt kompozit rezin restorsayonlarla tedavi edilmiştir. Dişlerin renk seçimi ve izolasyonunun ardından etch and rinse sistem (Single Bond 2) diş yüzeylerine uygulanmış ve nanohibrit rezin kompozit (Filtek Ultimate) üretici firmanın önerileri doğrultularında dişlerin mezial yüzeylerine tabakalı olarak uygulanmıştır. Direkt adeziv restorasyonlar, hastanın son kontrolleri sırasında klinik olarak başarılı kabul edilmişlerdir. Direkt adeziv restorasyonlar, diastemaların tedavisinde, estetik, fonksiyonel ve biyolojik olarak kabul edilir ve önerilebilirler.

\section{ANAHTAR KELIMELER}

Adezyon, diastema, direkt anterior adeziv restorasyonlar, estetik, klinik değerlendirme

Diastema, diş boyutundaki farklılıklardan (dar ya da konik şekilli dişler gibi) ya da arktaki boşluk ve diş boyutu arasındaki farktan kaynaklanabilmektedir. Diş kaybı ya da tam sürmemiş dişler de diastemaya neden olabilmektedir. Çenede yaygın olarak bulunan birden fazla diastema ise "polidiastema" olarak adlandırımaktadır. Polidiastema genetik, kötü alışkanlıklar ya da sistemik hastalıklar nedeniyle meydana gelebilmektedir. Bu durum çoğu birey için önemli estetik kaygıları beraberinde getirmektedir (Hwang ve ark 2012). Hiç kuşkusuz ki özellikle ön bölgede karşımıza çıkan diastemalar uygun estetik yaklaşımlarla tedavi edilebilmektedir (Wolff ve ark 2010).

\section{ABSTRACT}

Polidiastema closure using direct adhesive restorative systems: Two case reports

Closure of diastemas with direct adhesive restorative materials is considered to be practical and conservative. Adhesive resin composite technology enables dentists to add composite material to tooth surfaces to close gaps and reshape tooth form without cavity preparation. This case report describes two cases on diastema closure in anterior teeth with the management of two patient with multiple diastemas and bilateral tooth agenesis. In this case reports the diastemas were closed with direct composite resin restorations in one appointment without any preparation. After the shade selection (Vita Shade Guide,VITA Zahnfabrik, Germany) and isolation, etch and rinse adhesive system (Single Bond 2, 3M ESPE, St.Paul, MN, USA) was applied to teeth surfaces and nano hybrid resin composite (Filtek Ultimate, 3M ESPE, St.Paul, MN, USA) were layered on mesial surfaces of the teeth according to the manufacturers's instructions. The direct adhesive restorations were observed clinically acceptable at final examination. Direct adhesive restorations can be accepted and recommended as an esthetic, functional, and biologically sound treatment option for diastema closure.

\section{KEYWORDS}

Adhesion, diastema, direct anterior adhesive restorations, esthetics, clinical evaluation

Geçmişte ön bölge şekil bozukluklarının ve diastemaların giderilmesinde, dokularda geri dönüşümsüz madde kaybının oluşturulduğu, kron restorasyonları gibi protetik yaklaşımlar uygulanırken (Frese ve ark 2013), günümüzde ön bölge dişlerde karşılaşılan estetik sorunların giderilmesinde ortodontik tedavi, laminalar ve direkt adeziv restorasyonlar gibi çok farklı tedavi alternatifleri uygulanmaktadır (Wolff ve ark). Tüm bu uygulamalar içerisinde direkt adeziv restorasyonlar, klinisyenlere çok daha konservatif ve pratik bir yaklaşım şansı tanımaktadır (Heymann ve ark 1985). Adeziv teknolojinin diş hekimliğine kazandırılması sonrasında kompozit rezinler, diş dokularına olan üstün bağlanma kuvvetleri ile herhangi bir doku kaybı gerektirmeksizin

\footnotetext{
${ }^{1}$ Medipol Üniversitesi Diş Hekimliği Fakültesi Restoratif Diş Tedavisi Anabilim Dalı, İstanbul
} 
ya da minimum doku kaybı ile tedaviye olanak sağlamışlardır (Buonocore 1955). Direkt adeziv restorasyonlar ile estetik problemlerin önüne geçilmesi, diğer tedavi seçeneklerinden farklı olarak restoratif prosedürün geri dönüştürülebilir ve kolay tamir edilebilir olmasının yanı sıra, uygulama kolaylığı ve uygun maliyete sahip olması gibi avantajları da beraberinde getirmektedir (Hwang ve ark 2012). Ön dişlere uygulanan direkt estetik yaklaşımların uygulanması sırasında dikkat edilecek noktalar literatürde keskin şartlarla belirtilmiştir. Uygulanan restoratif materyal diş dokusuna renk, ton ve karakter olarak uyum sağlamalı; uygun karşıt ve komşu diş kontakt temaslar sağlanmalı; gingival dokuda oluşturulabilecek hasarlardan kaçınılmalıdır. Restorasyonun daha uzun ömürlü ve klinik olarak daha başarılı olabilmesi için gerekli adeziv prosedürler başarılı bir şekilde yerine getirilmelidir (Croll ve Cavanaugh 1990). Bu çalışmanın amacı polidiestama'ya ve lateral diş eksikliğine bağlı olarak estetik problemlerle kliniğimize başvuran iki hastamızda uyguladığımız ön bölge direkt adeziv rezin restorasyonların klinik başarısını ve klinik takip sonuçlarını sunmak ve değerlendirmektir.

\section{OLGU SUNUMU}

Ön grup dişlerdeki polidiastemaları nedeniyle farklı zamanlarda TC İstanbul Medipol Üniversitesi Diş Hekimliği Fakültesi Restoratif Diş Tedavisi kliniğine başvurmuş 1 kadın ve 1 erkek hastanın olgu sunumları anlatılmaktadır.

\section{OLGU 1}

Üst ve alt çene ön bölge dişleri arasındaki polidiastemadan dolayı estetik problemlere sahip 51 yaşındaki bayan hastanın yapılan muayenesinde, periodontal olarak sağlıklı olduğu, normal vertikal ve horizontal kapanışa ve kanin koruyuculu oklüzyona sahip olduğu gözlenmiştir. Hastanın diastemalarının, üst çenede 13-23, alt çenede 33-43 nolu dişleri kapsayan aralıkta olduğu belirlenmiş ve bu alanda bulunan tüm dişlerin restore edilmesi düşünülmüştür (Resim 1A). Hastanın, şikayetlerinin giderilmesi ile ilgili tedavi alternatifleri hakkında bilgilendirilmesinin ardından alınan ortak karar ile tedavinin direkt adeziv restorasyonlar ile gerçekleştirilmesine karar verilmiştir. Dişlerin profilaktik tedavilerinin ardından, renk seçimi (VITA Zahnfabrik, Almanya) gerçekleştirilmiş ve gözlenen diş boşlukları ve boşluga komşu dişlerin boyutları bir kumpas yardımı ile ölçülerek uygun tedavi planlaması gerçekleştirilmiştir. Ekartörün ağız içerisine yerleştirilmesini takiben izolasyon rulo pamuklar ile sağlanmış ve diş eti oluğu sıvısı akışını önlemek üzere retraksiyon kordu yerleştirilmiştir (Ultrapak, Ultradent, South Jordan, UT, ABD).

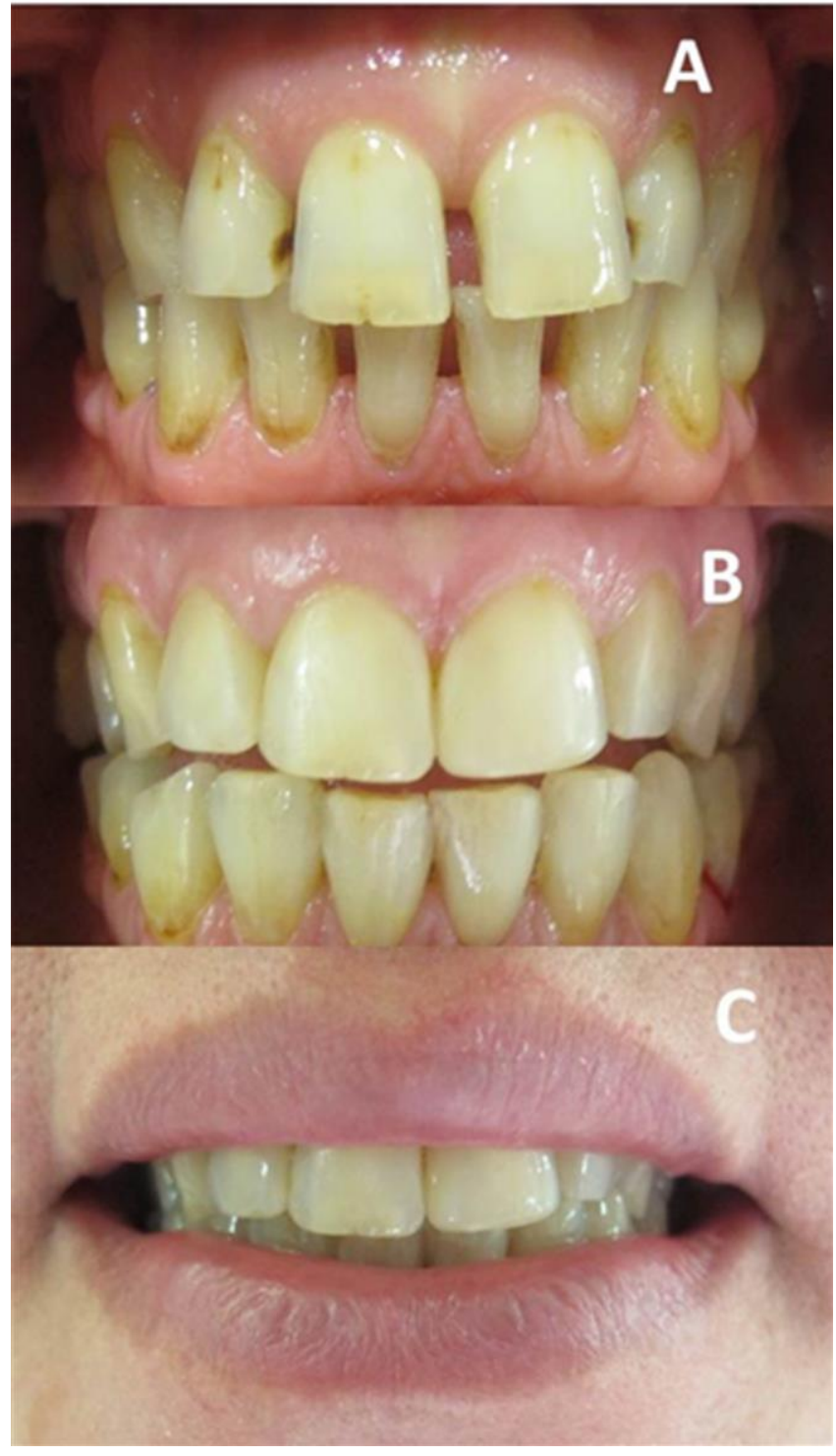

Resim 1.

Olgu 1'de açıklanan hastanın başlangıç (A) ve tedavi sonrası (B ve C) görünümü

Restore edilmesi planlanan diş yüzeylerine 60 sn boyunca \%37' lik fosforik asit (3M Etching gel, 3M ESPE, St. Paul, MN, ABD) uygulanmıştır. Asitin dikkatli bir şekilde 60 sn su ile yıkanması ve kurutularak tebeşirimsi mine görüntüsü elde edilmesi sonrasında adeziv rezin (Single Bond 2, 3M ESPE, St. Paul, $M N, A B D)$ uygulanmış ve üretici firmanın önerileri doğrultusunda 20 sn LED ışık cihazı (Guilin Woodpecker Medical Instrument Co., Ltd., Guangxi, Çin) ile polimerize edilmiştir. Kompozit şeffaf matriks bandı (Kerr\&Hawe, Orange, CA, ABD) ikiye kesilip dişeti oluğuna yerleştirilmiş ve parmak basıncı ile sabitlenmiştir. Nanohibrit rezin kompozitin (Filtek Ultimate, 3M ESPE, St. Paul, MN, ABD) mine tabakası ile palatinal ve aproksimal kısımlar bir çerçeve oluşturacak şekilde yerleştirilmiş ve polimerize edilmiştir (Resim 2). Daha sonra dentin dokusunu 
edebilmek amacı ile dentin tabakası uygulanmış ve polimerize edilmiştir. En üst tabaka ise tekrar mine kompoziti ile oluşturulmuş ve 40 sn polimerize edilmiştir. Polimerizasyon işlemi tamamlandıktan sonra şeffaf bant uzaklaştırılmış, hastanın kapanışı artikülasyon kağıdı ile kontrol edilerek yükseklikler giderilmiştir. Bitirme işlemleri için öncelikle su soğutması altında sarı bantlı elmas knife-edge frez (Acurata, Almanya) kullanılarak önce kaba bitirme ve konturlama ve işlemi yapılmış; ardından aşındırıcı diskler (Opti Disc, Kerr,Orange, CA, USA) ve lastikler (HiLusterPLUS Polishing System, Kerr,Orange, CA, USA) kullanılarak polisaj işlemi tamamlanmıştır. Tüm dişler aynı yöntemle, aynı hekim tarafından restore edilmiştir (Resim 1B, 1C).

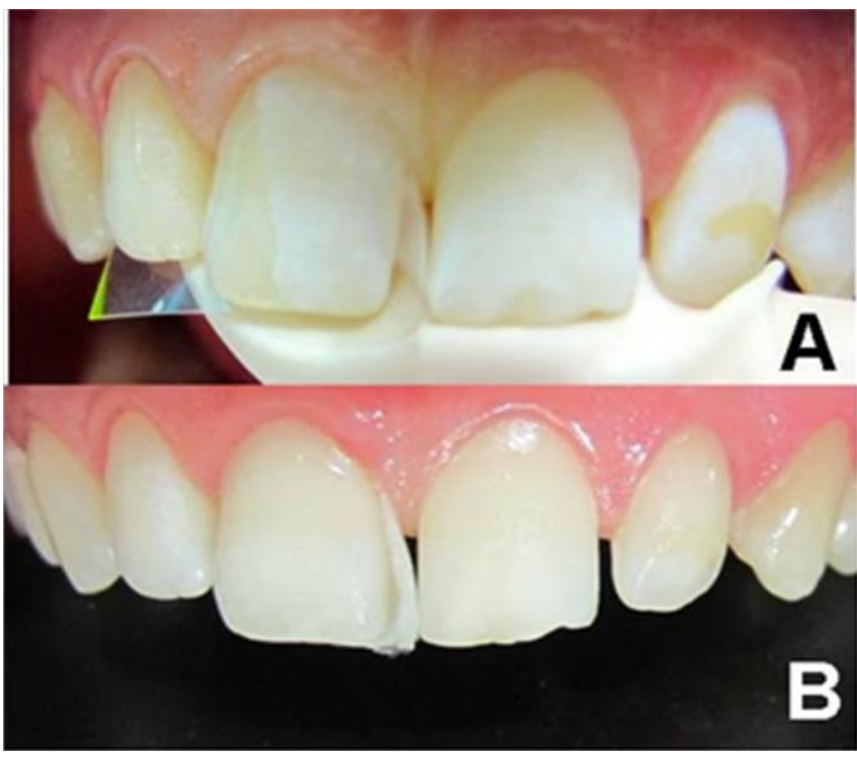

Resim 2.

Nanohibrit rezin kompozitin (Filtek Ultimate, 3M ESPE,St. Paul, MN, ABD) mine tabakası ile palatinal ve aproksimal kısımlar bir çerçeve oluşturacak şekilde yerleştirilmesi

Hastanın oral hijyen motivasyonu sağlanmış ve 6 ayda bir rutin kontrollere gelmesi belirtilmiştir. 6, 12, 24 ve 31 ay (Resim 3A, 3B, 3C) kontrollerinde hasta memnuniyetinin olduğu, restorasyonların klinik olarak başarılı olduğu, yalnızca restorasyonların sigara kullanımına bağlı bir miktar renklenme gösterdikleri tespit edilmiştir. Gerekli profilaktik yaklaşımlardan sonra restorasyonlara tekrar bir polisaj işlemi uygulanmıştır.

\section{OLGU 2}

Üst ve alt çene ön bölge dişleri arasındaki polidiastema ve üst lateral diş eksikliği nedeniyle estetik problemlere sahip 22 yaşındaki erkek hastanın yapılan muayenesinde, periodontal olarak sağlıklı, normal vertikal ve horizontal kapanışa sahip olduğu

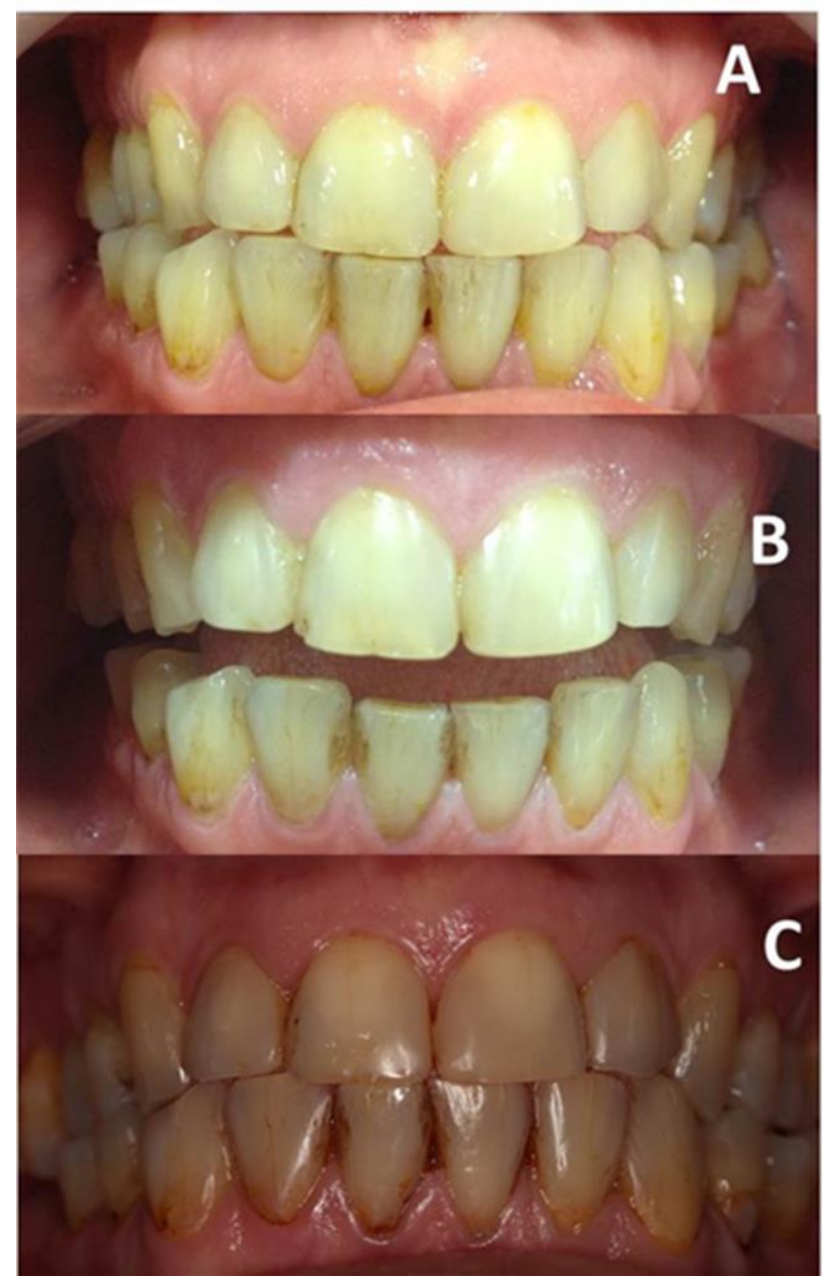

Resim 3.

Olgu 1'de açıklanan hastanın 12 (A), 24 (B) ve 31 (C) ay sonrasındaki kontrollerinde izlenen görünümü

lateral eksikliğine bağlı olarak 13-23 nolu dişler arasında alt çenede ise diastemaların 32 ile 42 nolu dişler arasında olduğu tespit edilmiştir (Resim 4A). Hastaya uygulanabilecek tedavi alternatifleri anlatıldıktan sonra alınan ortak karar ile sadece üst bölgedeki boşlukların kapatılmasının direkt adeziv restorasyonlar ile gerçekleştirilmesine karar verilmiştir. Dişlerin profilaktik tedavilerinin ardından renk seçimi gerçekleştirilmiş ve gözlenen diş boşlukları ve boşluğa komşu dişlerin boyutları bir kumpas yardımı ile ölçülerek uygun tedavi planlaması gerçekleştirilmiştir. Dişlerin izolasyonu ve adeziv prosedürler ilk vakada anlatıldığı gibi gerçekleştirilmiştir (Resim 4B).

Restorasyonların yukarıda anlatıldığı üzere tamamlanmasının ardından hastanın oral hijyen motivasyonu sağlanmış ve 6 ayda bir rutin kontrollere gelmesi önerilmiştir. Hasta 2 yıllık kontrolü sırasında alt dişlerdeki boşlukların da kapatılmasını istemiş ve hastanın alt dişlerindeki diestamaların restorasyonları da yine Olgu 1'de anlatıldığı şekilde gerçekleştirilmiştir (Resim 4C). Alt bölgedeki polidiastemaların 
giderilmesinin ardından birinci yıldaki kontrolde hastanın sigara kullanmaya başlaması nedeni ile renklenmelerin oluştuğu gözlenmiştir (Resim 4D) ve bununla birlikte hastanın restorasyonlarından memnun olması nedeni ile restorasyonlara tekrar polisaj uygulanmış ve klinik olarak kabul edilir oldukları belirtilmiştir.

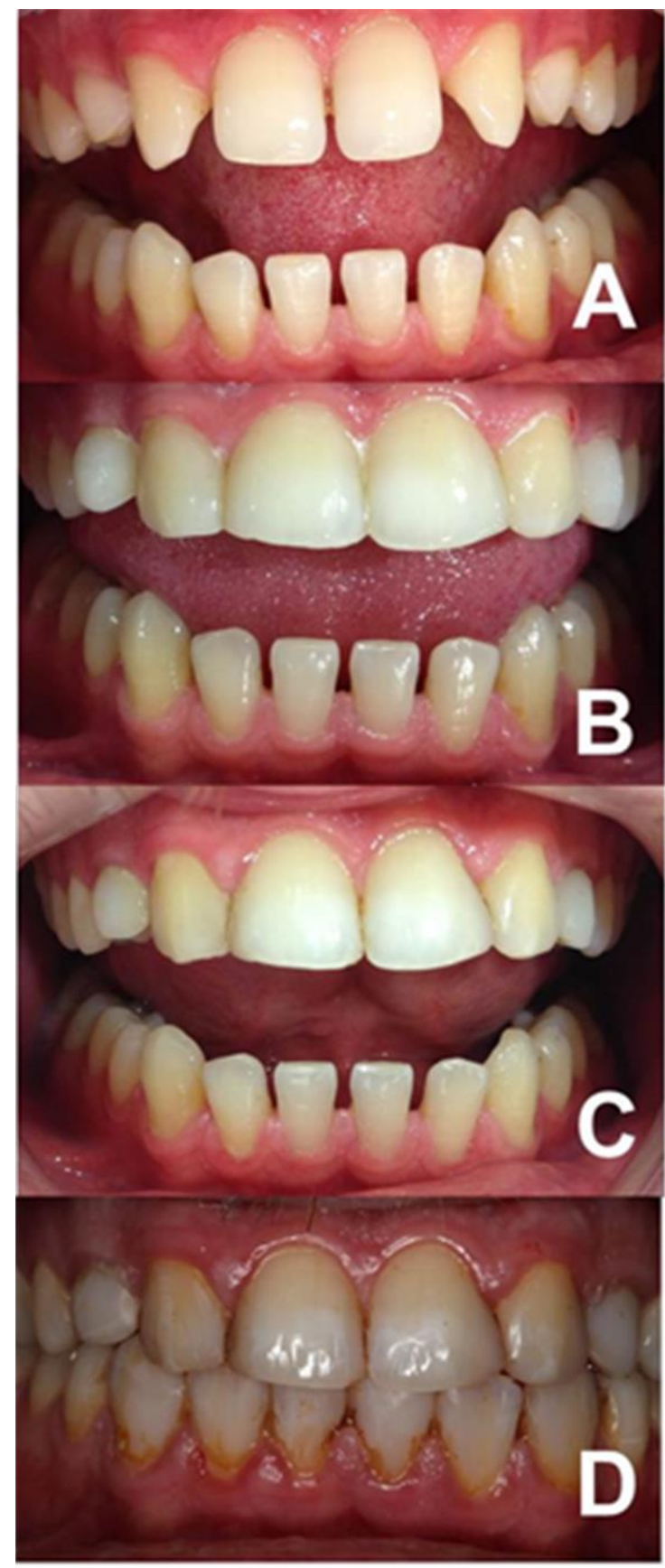

Resim 4.

Olgu 2'de açıklanan hastanın tedavi öncesi görünümü (A), üst çenenin tedavisi sonrasındaki görünümü (B), üst çene restorasyonların 2. yıl kontrol görünümü $(C)$ ve alt çene restorasyonların 1. yıl kontrol, üst çene restorasyonların 3. yıl kontrol görünümü (D)

\section{TARTIŞMA}

Günümüz diş hekimliğinde diş şekil bozukluklarının ve diastemaların direkt adeziv restorasyonlarla giderilmesi oldukça popular bir tedavi yaklaşımı haline gelmiştir (Lacy 1998). Çoğu hasta ve diş hekimi, sıklıkla uygulanan bu tedavi alternatifinin çok farklı kazanımlarına sahip olmuşlardır. Bu kazanımlardan ilki dişe uygun şekil, renk ve pozisyonun tek seansta kazandırılabilmesidir. Bu teknik genellikle non-invaziv ya da minimal invazivdir ve gerekli durumlarda geri döndürülebilir restorasyonlardır. Ufak kırıklar ya da hataların tamir edilebilmesi, diğer alternatif tedavi seçeneklerine kıyasla çok daha kolaydır. Bununla birlikte, büyük kırıklarda ya da restorasyon kayıplarında daha farklı alternatif tedavilere olanak sağlar. Tüm bu kazanımlara ek olarak direkt adeziv restorasyonlar, uygun maliyetli, laboratuvar aşaması gerektirmeyen hekim için kolay ve keyifli uygulamalardır (Wolff ve ark 2010). Fakat direkt yöntemlerin belirtilen avantajlarına rağmen bu materyallerin kırılgan olmaları, yüzey pürüzlülüğü, mikrosızıntı, polimerizasyon büzülmesi göstermeleri ve aşınma dirençlerinin düşük olması gibi dezavantajları da vardır (Tugut ve ark 2009). Bununla birlikte, ağız dışında polimerizasyonu tamamlanan indirekt kompozit rezinler ve seramik esaslı restorasyonların ağız sıvılarından daha az etkilenmesi ile renk stabilitelerinin direkt adeziv restorasyonlardan daha başarıı olduğu da vurgulanmıştır (Walls ve ark 2002). Sunulan iki olguda da sigara kullanımına bağlı renklenmeler izlenmiş ve polisaj prosedürleri ile giderilmeye çalışımıştır. Hastalardan alınan geri bildirime göre restorasyonların hastanın beklentilerini karşıladığı kanısına varımış ve restorasyonlar klinik olarak kabul edilebilir bulunmuştur. Estetik kazanım hassasiyetini yüksek olduğu bölgelerde direkt adeziv rezin restorasyonların seramik restorasyonlar gibi mineye benzer yansımayı ve şeffaflı̆ı sağlayamadıkları da belirtilmiştir (Yuzugullu 2005). Bu görüş seramik dolduruculu ve mine, dentin gibi farklı opasite derecelerinin yanı sıra daha geniş renk skalasına sahip olan kompozit rezinlerin diş hekimlerinin kullanımına sunulması ile geçerliliğini yitirmeye başlamıştır (Lee ve ark 2002). Çalışmamızda nanoteknolojinin diş hekimliğine üstün kazanımları ile klinisyenlerin kullanımına üstün estetik ve dayanıklılık özellikleri vurgulanan nanohibrit bir rezin kompozit tercih edilmiştir.

Direkt adeziv restorasyonlar literatürde, genel olarak ümit vaat edici sonuçlara sahip olarak belirtilmişlerdir. Daha dayanıklı, daha kalıcı ve diş dokusunu daha iyi taklit edebilir oldukları da vurgulanmaktadır (Manhart ve ark 2004). Ön bölgede uygulanan direkt adeziv restoratif materyaller, başarıı estetik sonuçlara olanak sağlarken, uzun ömürlü ve indirekt restorasyonlarla karşılaşııııldıklarında daha ekonomik materyallerdir (Macedo ve ark 2006). 


\section{SONUÇ}

$\mathrm{Bu}$ olgu sunumu, günümüz dis hekimliginde direkt adeziv restorasyonların uygun bir endikasyon ve iyi bir hasta motivasyonu ile doğru koşullarda uygulandıklarında, anterior dislerin farklı bölgelerinde estetik amaçla uygulanacak restorasyonlarda, konservatif olarak tercih edilebilinecek en uygun klinik seçeneklerden biri olduğunu göstermiştir. 


\section{KAYNAKLAR}

Buonocore MG, 1955. A simple method of increasing the adhesion of acrylic filling materials to enamel surfaces. $J$ Dent Res, 34(6), 849-853.

Croll TP, Cavanaugh RR, 1990. Augmentation of incisor width with bonded composite resin: another look. Quintessence int, 21(8), 637-641.

Frese C, Schiller P, Staehle HJ, Wolff D, 2013. Recontouring teeth and closing diastemas with direct composite buildups: a 5-year follow-up. J Dent, 41(11), 979-985.

Heymann HO, Hershey HG, 1985. Use of composite resin for restorative and orthodontic correction of anterior interdental spacing. J Prosthet Dent, 53(6), 766-771.

Hwang SK, Ha JH, Jin MU, Kim SK, Kim YK, 2012. Diastema closure using direct bonding restorations combined with orthodontic treatment: a case report. Restor Dent Endod, 37(3), 165-169.

Lacy AM, 1998. Application of composite resin for singleappointment anterior and posterior diastema closure. Pract Periodontics Aesthet Dent, 10(3), 279-286.

Lee YK, Lim BS, Kim CW, 2002. Effect of surface conditions on the color of dental resin composites. J Biomed Mater Res, 63(5), 657-663.

Macedo G, Raj V, Ritter AV, 2006. Longevity of anterior composite restorations. J Esthet Restor Dent, 18(6), 310311.

Manhart J, Chen H, Hamm G, Hickel R, 2004. Buonocore Memorial Lecture. Review of the clinical survival of direct and indirect restorations in posterior teeth of the permanent dentition. Oper Dent, 29(5), 481-508.

Tugut F UnM, Kapdan A, Demir H, Dogan OM, 2009. Komplike kron kırıgı olgusunda cam fiber post destekli kompozit restorasyonu: olgu raporu ve 18 aylık takip. AU Dis Hek Fak Derg, 19(3), 207-212.

Walls AW, Steele JG, Wassell RW, 2002. Crowns and other extra-coronal restorations: porcelain laminate veneers. $\mathrm{Br}$ Dent J, 193(2), 73-76.

Wolff D, Kraus T, Schach C, et al, 2010. Recontouring teeth and closing diastemas with direct composite buildups: a clinical evaluation of survival and quality parameters. J Dent, 38(12), 1001-1009.

Yuzugullu B TS, 2005. Renk degisimine ve mine erozyona ugramıs dislerde laminat veneer restorasyon seceneklerin endikasyon bakımından karsılastırıması. CU Dis Hek Fak Derg 8(2), 133-137.

\section{Yazışma Adresi:}

Yrd. Doç. Dr. Tuğba TOZ AKALIN

Medipol Üniversitesi

Restoratif Diş Tedavisi AD, İstanbul

e-E-mail: ttoz@medipol.edu.tr 